\title{
A inserção indígena nos museus
}

\author{
Mariane Aparecida do Nascimento Vieira*
}

VIEIRA, M. A inserção indígena nos museus. R. Museu Arq. Etn., 30: 118-130, 2018.

Resumo: Este trabalho se reporta a algumas ações de curadoria compartilhada dentro de museus, examinando mudanças institucionais, discursivas e pragmáticas que vêm se dando, a partir principalmente dos debates pós-modernos e pós-coloniais em torno da imagem indígena tal como fora produzida/representada por meio das coleções museológicas de um período de "construção nacional". Se a partir do século XVI as coleções foram formadas na chave do exótico, que por sua vez confirma o paradigma evolucionista e civilizatório, a atuação dos índios nas instituições de guarda problematiza a apropriação ocidental da imagem acionada pelos artefatos, inclusive naqueles reunidos pelos próprios indígenas para formar as coleções de seus museus. Em outro viés, complementar, a internet aparece como um meio para a reapropriação ou repatriação imagética, como mostra o site Roots2Share.

Palavras-chave: Curadoria Compartilhada; Museus; Indígenas; Imagem; Repatriação.

\section{Territórios (re)conquistados}

presente artigo parte das trocas interculturais dentro do que chamaremos de curadoria compartilhada nos museus. ${ }^{1}$ As coleções compostas de artefatos indígenas começaram a ser formadas no período da expansão europeia, no final do século XV. Viajantes europeus tiveram contato com coletividades até então desconhecidas para eles e iniciaram trocas de alimentos, ferramentas, além de coletarem espécimes nativos da fauna e da flora. Nesse contexto, os objetos também

1 artigo versa sobre questões trabalhadas na dissertação de mestrado intitulada Narrativas dos ameríndios: disseminação de uma visão do contemporâneo, defendida em 2017, no Programa de Pós-Graduação em Memória Social, da Universidade Federal do Estado do Rio de Janeiro (PPGMS/UNIRIO), sob orientação do Prof. Dr. Amir Geiger.

* Doutoranda do Programa de Pós-Graduação em Antropologia Social do Museu Nacional da Universidade Federal do Rio de Janeiro (PPGAS/UFRJ). <mariane.anv@gmail.com> eram reunidos como representativos dos povos encontrados, e interpretados pelo signo da curiosidade, assim como serviam enquanto prova material da ida a estes territórios. As novas terras foram associadas ao paraíso perdido, o Éden (Hollanda 2004) descrito na Bíblia, e seus habitantes, como um povo puro a ser educado e catequizado. No entanto, tal visão idílica não se manteve e a pretensa selvageria dos nativos apareceu recorrentemente ressaltada, principalmente na alusão ao canibalismo (Lestringant 1997). ${ }^{2}$

2 Na construção de imagens, no mínimo, ambíguas dos indígenas do dito Novo Mundo pelos europeus identificamos sinais da agência desses povos. Viveiros de Castro (2002: 206) aponta que se os europeus viam nos índios a possibilidade de estender sua cultura, impondo os costumes europeus e introduzindo a religião cristã, e os indígenas ao serem confrontados com os europeus enxergaram a possibilidade de "alargar sua condição humana”. Ao contrário da concepção europeia, principalmente das queixas missionárias, os índios, longe de possuírem memória e vontade fracas, se apropriavam do que lhes interessava na cultura do outro. 
Quanto aos seus artefatos, ao serem reunidos em coleções e inseridos em instituições de memória, foram ressignificados à luz de narrativas que serviram ao regime colonial. A imagem dos indígenas passou a ser associada a teorias evolucionistas que os colocavam em um momento inicial do desenvolvimento humano, imagem que teve continuidade até o início do século XX (Cunha 1992). O evolucionismo foi uma forma de explicar a diversidade, às custas da inferiorização do outro, e, para entender as narrativas que foram associadas às coleções de acordo com essa teoria, podemos nos ater ao descobrimento ou invasão do que foi chamado de Novo Mundo. Juan Ginés de Sepúlveda (2012), e Bartolomé de las Casas (2012) travaram um intenso debate em torno do lugar do indígena no mundo, entre 1550 e 1551 (Serna 2012: 385). Enquanto o primeiro utilizou seus conhecimentos filosóficos e teológicos para destacar a inferioridade dos índios, defendendo inclusive sua escravização e imposição da fé cristã, o segundo, sob uma perspectiva humanista, defendeu a soberania dos povos indígenas.

$\mathrm{Na}$ ausência de escrita alfabética dos grupos colonizados, sua imagem foi narrada pelo olhar equivocado (ou, para ser mais preciso, interessado em sua subjugação) de seus invasores, cuja autodesignação como colonizadores mostra perfeitamente que a teoria evolucionista foi resultado de um processo pensado e praticado como assimétrico. Na parte do Novo Mundo colonizada pelos espanhóis, os indígenas possuíam escrita ideográfica, além da presença de cronistas indígenas que utilizaram a escrita alfabética, tendo na figura de Felipe Guamán Poma de Ayala um ótimo exemplo. Em sua Primer Nueva Coronica y Buen Gobierno (1612-1615), dirigida ao rei espanhol, descreve o governo indígena, ressaltando a ordem cósmica que foi abalada pela "interferência" espanhola. Rivera Cusicanqui (2010), ao propor uma sociologia da imagem, identifica na obra de Poma de Ayala uma narrativa indígena que fugiu ao controle colonial utilizando um signo e uma ferramenta de sua imposição, a escrita alfabética e recorrendo a imagens que mostram o empequeñecimiento dos indígenas diante da expropriação de seus domínios, da violência e da exploração perpetrada pelos espanhóis. Podese dizer que, se Poma de Ayala narrou o bom governo indígena, essa mesma narrativa, de forma simétrica, evidencia também a barbárie espanhola.

A proposta que se seguirá é a de articular a imagem do indígena colonizado com a formação de coleções que se encontram salvaguardadas dentro dos museus. Dessa forma, a própria coleta de objetos passou por um movimento de "curiosidade" a "símbolo de inferioridade", assim como os indígenas passaram - na percepção europeia - de inocentes a selvagens. A presença de indígenas dentro de instituições museológicas pode atuar como um direcionamento para a curadoria de tais coleções (tanto as reunidas sob o signo colonial quanto as contemporâneas) sob o "bom governo" indígena. Portanto, o argumento de forma frouxa é de que o ocidente produziu dois movimentos: (a) privilegiou a escrita alfabética, desconsiderando outras formas de linguagem; e (b) apropriou-se dos objetos indígenas e os colocou em suas instituições. A inserção indígena é apenas um primeiro movimento para disseminar outras formas de narração e desconstrução de sua imagem construída por seu colonizador de forma criativa. Nesse sentido, a curadoria compartilhada aparecerá como uma pista do caminho a ser trilhado para que essa ideia seja disseminada.

\section{A imagem dos indígenas nas coleções}

As coleções particulares foram sendo formadas a partir do período das "grandes descobertas”, coleções estas que viriam a incorporar o acervo de museus públicos a partir do final do século XVIII. Os acervos etnográficos eram expostos sem um tratamento expográfico que os contextualizassem, evidenciando uma pretensa inferioridade dos povos colonizados. Da mesma forma, esse uso demonstra a (falta de) ética que regeu as relações entre europeus e indígenas, sendo tais objetos testemunhos dessa usurpação. Nicholas Thomas mostrou que o interesse dos europeus em artefatos dos povos 
do Pacífico ao longo do século XVIII estava associado à curiosidade, o colecionamento não submetia os objetos a um julgamento estético, ${ }^{3}$ mas eles serviam como comprovação da própria ida às ilhas (Thomas 1991). Entretanto, no século XIX os objetos passaram a servir ao projeto colonial, sendo apropriados enquanto prova material da "selvageria" dos povos que os produziram, dentro de uma narrativa dita científica (Gualtieri \& Dantes 2001). Outro ponto significativo é o prestígio adquirido pelo colecionamento destes artefatos, o que também aparece em outros contextos, como o estudado por Françozo (2014) por meio da figura de Maurício de Nassau, que construiu uma coleção durante o período em que esteve no Brasil, mostrando que a circulação dos objetos - que foram dispersos mediante doações - perpassa as próprias relações interpessoais que ele estabeleceu na sociedade da corte, ao retornar para a Holanda.

Apesar do paradigma que embasou as teorias evolucionistas ter caído em desuso, a curadoria das coleções e a propriedade dos artefatos - muitos adquiridos de modo escuso, o que fornece pistas para a maneira como foram interpretados - continuou a cargo das instituições ocidentais. As narrativas museológicas atreladas a teorias antropológicas ajudaram a forjar a imagem das sociedades indígenas como parte da diversidade humana, como postulou Franz Boas (1955) enquanto curador das coleções etnológicas do Museu Americano de História Natural. No Brasil, essa diversidade apareceu na teoria das três raças, ao criar um mito de origem da formação do povo brasileiro pela união de brancos, negros e indígenas (Ribeiro 1995), submetendo as coleções indígenas expostas à imagem do Estado Nacional. Do mesmo modo que a teoria evolucionista atuou como uma forma de pacificar a alteridade, a teoria da diversidade apropriada

3 A estética à qual o autor se refere seria submeter os objetos coletados à concepção ocidental de belo, o que não ocorre nesse primeiro momento. Há exposições contemporâneas como a do Musée Quai Branly (Paris, França), que segue essa abordagem. pelo Estado Nacional Brasileiro serviu para criar um mito de origem da nação.

O movimento que objetivou mudar o regime da inserção indígena dentro dos museus está ligado a uma série de problematizações: por um lado, a antropologia passou a questionar seu papel enquanto disciplina que serviu diretamente aos colonizadores, lamentando o desaparecimento de seu objeto de estudo enquanto questionava seu próprio direito de "etnografar" outros povos (Stocking 1985); por outro, a museologia refletiu a respeito do distanciamento entre a instituição e os grupos que visava representar (Cândido 2003), estabelecendo possíveis diálogos com a crítica cultural e o questionamento da natureza cultural do que seja representar (Latour 1994). Nesse interim, dando margem a um processo de descolonização das narrativas - coincidente, em parte, com o fim das metanarrativas (Lyotard 2000) e com o movimento pós-colonial - e de intensificação e ampliação do protagonismo indígena, consideramos que o conceito pós-colonial pressupõe as relações e agudas diferenças entre as sociedades colonizadas e colonizadoras (Hall 2013), ao deslocar o eixo das discussões e considerar, por exemplo, as influências da colônia na metrópole.

\section{$\mathrm{Na}$ realidade toda a questão indígena} (e não só ela) está eivada de semelhantes reificações. No século XVI, os indios eram ou bons selvagens para uso na filosofia moral européia, ou abomináveis antropófagos para uso na colônia. No século XIX, eram, quando extintos, os símbolos nobres do Brasil independente e, quando de carne e osso, os ferozes obstáculos à penetração que convinha precisamente extinguir. Hoje, eles são seja os puros paladinos da natureza seja os inimigos internos, instrumentos da cobiça internacional sobre a Amazônia.

(Cunha 2009: 261)

Acompanhar esses deslocamentos nas imagens dos indígenas nos ajuda a vislumbrar a construção das narrativas em outras instâncias; entre elas, o museu. 


\section{Museus}

Criado durante a Antiguidade Clássica, o Mouseion - templo das Musas, ou Museu de Alexandria, mito de origem dos museus - não se assemelhava ao que conhecemos contemporaneamente como instituição museológica. Encontrava-se mais próximo de um arquivo e biblioteca que funcionava como um centro acadêmico, dedicando-se às artes da memória "que propunham a articulação de imagens a lugares e espaços, para assegurar a rememoração" (Meneses 2010: 15) e, era marcado pelo seu caráter monumental. Assim, o museu tem continuidade com outros campos do mito de origem ocidental, que retira seu poder de uma apropriação da herança grega (Trouillot 2003), associada ao berço das artes e ciências - outro campo seria a língua, por exemplo, a respeito da ideia de superioridade da escrita alfabética sobre outras (Goody 1996; 2006). A configuração museológica mais recente teve início a partir dos séculos XVI e XVII, com a criação de coleções particulares formadas por objetos de interesse artístico, histórico e científico em galerias que só viriam a ser efetivamente abertas ao público ao longo do século XVIII (Poulot 2013). Nos gabinetes de curiosidades que reuniam objetos com caráter pretensamente científico (Possas 2010) encontramos o prelúdio da lógica do patrimônio elaborada dentro do nexo do estado-nação (pós-Revolução Francesa), na qual os artefatos compuseram coleções etnográficas que atuaram e atuam enquanto meta-artefato de produção de narrativas sobre o "outro".

A partir da organização dos museus enquanto espaço de guarda, pesquisa e exposição, suas coleções foram acionadas através de narrativas diversas coincidentes com teorias antropológicas vigentes; ora foram exibidas como forma de representarem as sociedades que as produziram, ora pelo seu caráter estético (Fabian 2004; Stocking 1985). No que tange ao tratamento museológico, a Nova Museologia fruto do debate iniciado em 1972 no encontro organizado pelo International Council of Museums (Icom), no Chile, e difundida por meio das resoluções da mesa-redonda que sintetizou as diretrizes elencadas pelos profissionais presentes
- reafirmou a aproximação entre os museus e a sociedade, especificamente, o engajamento das instituições com as comunidades. Em vista disso, agentes que costumavam ser referenciados nos museus, mas sem atuação na elaboração das narrativas sobre si, passam a atuar conjuntamente com os profissionais que compõem o quadro de funcionários. Acompanhar os termos da atuação dos índios dentro dessas instituições pode funcionar como uma ferramenta de análise da descolonização do imaginário. ${ }^{4}$

Desse modo, esse território - o museu moderno - que serviu ao imperialismo, passa por um processo daquilo que Stengers (2015) chama de reclaimed, pelas sociedades minoritárias. A autora, ao tratar de uma série de eventos que vêm causando a "intrusão de Gaia" 5 e destacar o papel do discurso dos especialistas nas catástrofes, sugere que os assuntos recorrentemente associados à ciência podem ser reclamados e se tornar uma "questão comum", permitindo uma ação coletiva na busca de meios para pensar os problemas a partir de outras perspectivas. De forma semelhante, sugerimos que a inserção de agentes que vêm sendo representados nos museus por meio de seus objetos, pela narrativa dos especialistas, pode atuar diretamente na reformulação de sua imagem.

Resumindo o argumento: se o colecionamento foi pautado por séculos em um conhecimento sobre os outros, a partir da linguagem ocidental repleta de preconceitos e equívocos epistemológicos - como ilustramos

4 O que chamamos de inserção indígena nas instituições museológicas de maneira alguma é fruto de uma benevolência dos museus, mas uma pista de que os índios tiveram "notícias" de objetos sob a guarda de tais instituições e querem retomá-los. No filme Iauretê, Cachoeira das Onças (Carelli 2006), os índios Tariano ao visitarem o Museu do Índio, das freiras salesianas, vasculham e selecionam na reserva técnica objetos que querem "de volta", enquanto a postura institucional é de repatriá-los quando os indigenas conseguirem a infraestrutura para salvaguardá-los.

5 Isabelle Stengers (2015) configura a época em que vivemos como "tempo das catástrofes", marcado por mudanças climáticas intensificadas em decorrência de um modelo econômico de crescimento insustentável que, por sua vez, trouxe o que a autora qualifica como "intrusão de gaia". Gaia seria a natureza que se introduz, não como inquisidora mas como alguém que, ofendida, se torna imprevisível. 
no debate entre Las Casas e Sepúlveda - a inserção indígena em instituições como o museu pode funcionar como um outro mecanismo para conhecer os ameríndios através da sua própria elaboração curatorial.

\section{Curadoria compartilhada}

Antes de tratar propriamente da curadoria compartilhada, que envolve diversos atores (indígenas, antropólogos, museólogos, designers, arquitetos, conservadores, etc.), propomos a elucidação do conceito. Curadoria consiste na seleção do acervo, realização de pesquisas, ações de salvaguarda e comunicação, através de exposições de longa duração e temporárias, por exemplo. A princípio, a curadoria surgiu com as coleções das ciências naturais que se associavam à etimologia da palavra por requerem "a cura", ou seja, para que sua conservação ocorresse.

A figura do curador passa a se especializar e se desprender do conservador, aparecendo em diferentes instituições - tendo em mente os modelos de museus de história natural e de artes (Bruno 2008: 3).

Apesar da figura do curador remeter a uma atividade solitária, do especialista que conhece todos os meandros de determinado acervo, as discussões geradas pela Nova Museologia (ou, ainda, Sociomuseologia) apontam para uma produção comunitária, valorizando a interdisciplinaridade (Bruno 2008: 3). A curadoria se dá, portanto, por uma cadeia operatória que parte do objeto museológico e cria uma narrativa destinada ao público (Cury 2009). Contudo, exposições museológicas contemporâneas desafiam a ideia de que necessariamente a curadoria deverá partir do objeto, podendo privilegiar um conceito e a partir daí elaborar uma narrativa expográfica.

A curadoria compartilhada, colaborativa, ou, ainda, participativa é um processo de troca que constitui a curadoria das coleções, que tem na exposição seu principal meio de comunicação com o público. Agentes que recorrentemente eram retratados nas exposições, mas não participavam na construção narrativa passam a atuar dentro dos museus. Instituições, ao buscarem problematizar sua raiz colonial, promoveram a ida de grupos minoritários para conhecerem os acervos a que estão relacionados, incorporando novas relações com os objetos, além de desenvolverem ações em conjunto, como exposições, atividades educativas, cursos. Tais experiências nos mostram a potência do processo de "indigenização" dos museus (Roca 2015), como propomos argumentar.

A presença dos indígenas dentro destas instituições é anterior ao movimento que identificamos na metade do século XX; porém, ainda que se trate de outro tipo de inserção, o período colonial é recheado de exemplos de indígenas que foram expostos nos chamados zoológicos humanos (Morel 2000). A princípio, as instituições traziam os grupos indígenas para parcerias principalmente com o propósito de sanar dúvidas a respeito do acervo, ou seja, sua atuação estava submetida aos interesses do museu e não consistia em um processo colaborativo - o que nos atenta para o fato dessas relações não serem necessariamente simétricas. Esse cenário começou a se alterar por uma abertura institucional e, principalmente, pela demanda dos povos, grupos e associações ameríndias. A antropóloga Ann Finenup-Riordan (2010) relatou o interesse de seus amigos Yup'ik ao verem as fotografias de máscaras feitas por seus antepassados pertencentes ao acervo do Museum of the American Indian. ${ }^{6}$

O retorno das máscaras aos Yup'ik não implicava diretamente a repatriação dos objetos; por meio destes os mais velhos objetivavam mostrar as práticas culturais de seu povo para os jovens. O desejo se concretizou através da exposição Agayuliyararput / Our Way of Making Prayer, montada em Bering Sea, comunidade da baía Toksook, em 1996 - embora a propriedade das máscaras tenha continuado com o museu (Finenup-Riordan 2010). A parceria não se limitou à exposição, e entre os desdobramentos está uma visita de alguns Yup'ik aos museus que possuem objetos de sua etnia em seus acervos, como o Ethnologisches Museum, em Berlin (Alemanha), que possui mais de dois mil objetos desse povo. $\mathrm{Na}$ Europa, vários museus etnográficos criaram iniciativas semelhantes, levando diversas etnias

6 Um dos museus do Instituto Smithsonian, com sedes em Washington e Nova York (Estados Unidos). 
para colaborarem na curadoria das coleções manuseando os objetos, acrescentando dados à catalogação, desenvolvendo exposições e atividades no próprio museu e nos territórios desses grupos. Tais projetos encenam o "pagamento" de uma dívida. Não se pode mais ignorar os efeitos devastadores que as nações europeias - ao longo do processo mesmo em que se constituíram historicamente enquanto tais - causaram nos grupos dos territórios de que vieram a se apropriar.

As instituições brasileiras também têm desenvolvido maneiras para criar uma parceria com os povos dos quais possuem acervo, problematizando suas coleções. Além do museu em si, as universidades têm funcionado como um ponto canalizador da participação indígena na curadoria de seus acervos. Um exemplo disso é a atuação da Universidade de Pernambuco no auxílio aos povos indigenas que desenvolveram seus pontos de memória, resultando na criação de museus indígenas. No Sudeste, o Museu do Índio (RJ), instituição vinculada à Fundação Nacional do Índio (Funai), desde 2012 vem elaborando projetos com as sociedades indígenas. Ionne Couto (2012) conta como na elaboração do Plano Plurianual (PPA) do museu captaram recursos que possibilitaram a realização de projetos como a exposição Tempo e Espaço no Amazonas: os Wajãpi, resultado de um trabalho de sete meses que envolveu os Wajãpi, o corpo de funcionários do museu e a antropóloga Dominique Gallois. A exposição, além de um produto representado no percurso expográfico, possibilitou aquisições para o acervo de fotografias, objetos e filmes do universo simbólico e do cotidiano dessa etnia. Outro ponto é a presença recorrente dos indígenas como educadores do Museu do Índio, realizando atividades com o público em torno das exposições.

O Museu Nacional (RJ), primeira instituição museológica do país, também realiza parcerias nesse viés. Fátima Nascimento (2012) narrou projetos desenvolvidos pelo Setor de Etnologia desde o final da década de 1970, entre os quais destacamos "Os índios Tikuna como agentes de um processo de educação integrada”, que previu a criação de um centro de memória elaborado pelos Tikuna, e o projeto de restauração coordenado por Geraldo Pitaguary, que relatou o diálogo com os indígenas a respeito dos procedimentos e materiais a serem usados. O primeiro projeto, somado a outros que o antecederam, contribuiu para a criação do Museu Maguta (AM). No segundo projeto, os artefatos, para serem restaurados, suscitaram a necessidade de pesquisa e, principalmente, de um amplo diálogo com os indígenas. "Esse poderia ser um interessante meio de condução de uma curadoria compartilhada, já que para a maioria dos grupos indígenas a substituição de materiais ou parte de adornos é perfeitamente coerente com a ideia de conservação." (Nascimento 2012: 101). Deste modo, fica claro que os paradigmas da restauração brasileira, herdeira dos cânones italianos (em que se considera o mínimo de intervenção possível durante a restauração), não se aplicam a todos os casos e que a percepção indígena de "autenticidade" no manuseio destes artefatos é complexa.

O Museu Histórico e Pedagógico Índia Vanuíre, em Tupã (SP), ao ser inaugurado em 1966, salientava um discurso de pacificação dos Kaingang, ressaltando a figura de Vanuíre como uma personagem conciliadora.

\footnotetext{
De fato, Vanuire foi uma Kaingang trazida de Campos Novos do Paranapanema (atual Campos Novos Paulista) pelo SPI, como estratégia de atração dos Kaingang da região para que fossem aldeados. Assim, ela atuou como intérprete, como outros. Ela simboliza o fim dos conflitos, em 1912, que resultou no aldeamento dos Kaingang em duas áreas restritas, hoje as Terras Indígenas Vanuire e Icatu, localizadas respectivamente em Arco-Íris e Brauina (SP). A india Vanuíre faleceu em 1918 em Icatu, onde viveu seus últimos dias. (Museu Índia Vanuíre 2013)
}

Vanuíre é considerada por muitos como a grande "pacificadora", imagem que o museu quer desconstruir, pois reforça a visão negativa dos Kaingang implantada há um século. $\mathrm{O}$ museu respeita o simbolismo que envolve essa personagem, mas atua de modo crítico e histórico (Museu Índia Vanuíre 2013).

A narrativa repleta de equívocos só veio a ser reelaborada com a reinauguração 
da instituição, em 2010. Deste modo, a Índia Vanuíre passou de uma personagem que se uniu aos brancos, na integração dos indígenas do ideal nacional, para aquela que buscou meios para negociar com a violência dos colonizadores. A imagem da submissão indígena vem sendo questionada com a participação dos próprios Kaingang - além de outras etnias - na reformulação da narrativa propagada pelo museu.

A presença dos indígenas no museu pode ocorrer de formas tão abrangentes e variadas quanto suas possíveis articulações interculturais - então, potencialmente, cada articulação, mesmo molecular, seria um museu. ${ }^{?}$ Nos casos brevemente apontados, visamos mostrá-los enquanto articuladores essenciais não apenas no que incide nas coleções já existentes, mas principalmente para a possibilidade de criação de novas coleções, de pesquisas, projetos educacionais e curatoriais extensivos para além do espaço museológico e, no limite, novas direções, o que sinalizará uma mudança epistemológica.

Assim, a curadoria compartilhada ou coletiva se apresenta como uma das formas da inclusão desses agentes nas instituições museológicas enquanto coautores. Os casos citados mostram uma dinâmica rica no contato desses povos com os acervos com que possuem relações, não apenas enquanto fonte primária de informações sobre os artefatos, mas também enquanto pesquisadores e curadores. A figura do curador é especialmente intrigante por fornecer um paralelo para a própria escrita etnográfica, em que Clifford (1998) destaca quatro modos de autoridade: experiencial, interpretativo, dialógico e polifônico. Entre eles destacamos o polifônico, por dotar a produção do conhecimento etnográfico como parte de um processo em que o nativo tem

7 Consideramos como museu uma instituição sem fins lucrativos que possui coleções sobre as quais realiza pesquisas, ações de conservação, atividades educacionais e comunicacionais, como uma exposição, destinadas ao público. Por isso, as articulações entre indígenas e museus podem gerar a criação de coleções que atendam a essas características (de guarda, educacionais, comunicacionais etc.) e suscitarem dinâmicas similares (e além das) as produzidas no espaço institucional. um papel ativo na criação das narrativas. A curadoria compartilhada seria um tipo de escrita produzida por uma autoridade polifônica, criando uma narrativa curatorial em que diferentes agentes participam. $\mathrm{O}$ desafio está em estabelecer uma relação entre os agentes institucionais e esses povos marcada pela horizontalização, em que todos atuem no processo com o mesmo peso de decisão.

A presença dos indígenas em museus que guardam, pesquisam e expõem coleções criadas a partir de uma lógica colonial provoca uma retomada dessa materialidade negada a estes povos. Mais do que parceiros de entidades ocidentais, ocorreu o que podemos denominar de indigenização dos museus - dentro do que Sahlins (1997) chamou de indigenização da modernidade -, culminando na criação de instituições pelos povos indígenas. Como sinalizou James Clifford a respeito dos museus indígenas da costa noroeste dos Estados Unidos (Centro Cultura de U'mista e Museu Kwagiulth):

Eles são, sob aspectos importantes de sua existência, projetos da "minoria" ou da "oposição" no interior de um contexto museológico comparativo [em relação as instituições ocidentais]. Mas, sob outros aspectos cruciais, não são absolutamente museus, e sim prolongamentos das tradições indígenas de contar histórias, de colecionar objetos e de representálos visualmente. (Clifford 2009: 258-259).

Assim como nos Estados Unidos, museus indígenas foram criados em países como Canadá, México e Brasil, cada qual com suas particularidades. O Museu Maguta, a primeira instituição museológica indígena no contexto brasileiro, inaugurada em 1991 na cidade de Benjamin Constant (AM), surgiu em meio a uma mobilização pela demarcação das terras dos Ticuna (Oliveira 2012). Desta forma, o museu funcionou e funciona como uma ferramenta contracolonial ao atuar como um suporte de criação e difusão de memória e na angariação de aliados - a população da cidade começou a desconstruir preconceitos a respeito dos Ticuna (Freire 2009). 
O Museu Kanindé, na fala de Suzenalson Kanindé (informação verbal) ${ }^{8}$ surgiu a partir da coleção reunida pelo cacique Sotero, classificada por categorias nativas como "coisas dos índios", "coisas da natureza", "coisas dos velhos", "coisas da mata”, entre outras. A coleção, enquanto parte constitutiva do museu, atua como uma materialidade dos Kanindé, e não somente da pessoa do cacique. A atuação do museu se destaca pela ligação estreita com a escola, elaborando um trabalho de perpetuação da memória kanindé e valorização de sua cultura. No que tange à curadoria compartilhada, Suzenalson evidencia a presença do grupo dentro da instituição - contrastando com as instituições ocidentais em que a figura prestigiosa do curador costuma ser associada a um único indivíduo para cada coleção. Os objetos do cacique circulam, são uma "materialidade" (inclusive dos comportamentos, ações e saberes de que dependeu sua produção /obtenção/conservação), que percorre ciclos sociais complexos, de modo tal que conserva, isto é, colabora com a continuidade ou memória de certas relações intra - e intergrupais. Esses artefatos e sua circulação não devem ser pensados apenas como instrumentais, mas envolvendo valor, narrativas, percepções, habilidades etc., que constituem a autoria coletiva do modo de vida do grupo.

Retomando a ideia inicial desta sessão, sinalizamos os diversos meios em que tal inserção indígena pode ocorrer, aparecendo sob o conceito de curadoria compartilhada ou não: enquanto pesquisadores, educadores, conservadores etc.

\section{Repatriação imagética}

O último ponto a ser elucidado aponta para uma possibilidade de repatriação de bens sob guarda de museus ocidentais aos indígenas, tornando viável sua própria curadoria dessa

8 Comunicação oral proferida na exposição "Dja Guata Porã: Rio de Janeiro Indígena”, Museu de Arte do Rio, Rio de Janeiro, 26 de julho 2017. coleção, que literalmente está vinculada à imagem dos gronelandeses.

A repatriação de imagens (e coleções) indígenas será aqui abordada metodologicamente com referência à internet, entendida como meio comunicacional no qual um conjunto de saberes (inclusive programação) pode produzir e acionar ferramentas ou artefatos pragmáticos e discursivos. Como condutor da discussão, uma breve descrição do site Roots2Share - entendido aqui como uma instância desses "artefatos virtuais" de comunicação e produção de realidade - ajudará a pensar a possibilidade de apropriação dessa proposta para outros contextos. A escolha por abordar o tema através de uma ferramenta elaborada por museus holandeses vem como um vislumbre de percurso possível para não só horizontalizar o acesso às coleções - em especial, a garantia de acesso por parte dos grupos aos quais os objetos estão "originalmente" associados -, mas igualmente propiciar usos e narrativas autônomos de objetos e de símbolos culturais pelos povos vinculados ao acervo.

O Museum Volkenkunde, em Leiden (Holanda), implementou em novembro de 2007 um projeto piloto chamado Sharing Knowledge $\&$ Cultural Heritage, First Nations of the Americas (SK\& $\mathrm{CH}$ ), que consistiu em convidar lideranças indígenas e especialistas (não indígenas) no campo das Américas e Europa para discutirem vários aspectos em torno do trabalho com a cultura material (Buijs \& Van Broekhoven 2010: 7). ${ }^{9}$ Essa reunião de três dias acionou uma posição política da instituição em desenvolver projetos com comunidades, como a proposta de digitalizar e disponibilizar seu acervo on-line e desenvolver exposições junto com os povos dos quais possui artefatos. Esse tipo de experiência atua na desnaturalização da formação de coleções museológicas, evidenciando os interesses e processos por trás das seleções que precedem essa formação e enriquecendo os desdobramentos ao trabalhar

9 O registro dessa reunião está na publicação disponível em: <https://bit.ly/2SMNHbk>. Acesso em: 29/07/2017. 
com comunidades não subordinadas à dinâmica institucional.

O site Roots2Share é fruto de uma parceria entre dois museus holandeses: o Museon e o Museu Nacional de Etnologia. Ambos possuem fotografias tiradas no leste da Groelândia, por Gerti e Noortje Nooter, entre 1965 e 1986. Através dessa plataforma os groenlandeses têm acesso a fotos de seus antepassados que estavam guardadas em museus europeus. $\mathrm{O}$ interessante do projeto é a possibilidade de escrever no site, anotar histórias e perguntas pessoais..$^{10}$

O site é dividido em seis itens: about, photos, stories, photo map, collection, login. Em about há a proposta do projeto e as normas de utilização da plataforma, bem como a permissão de reprodução das fotografias, desde que sejam respeitadas as condições institucionais. A página photos permite o acesso integral à coleção de fotografias, enquanto em stories há fotos com a intervenção de usuários contando histórias associadas a elas. Em photo map encontra-se a localização geográfica das cenas originalmente retratadas. No acesso collection, pode-se fazer uma pesquisa localizada nas coleções de cada região da Groelândia. A última página é de acesso interno pelo login. Apesar das stories contabilizarem apenas 12 e serem vítimas de comentários anônimos de trolls ${ }^{11}$, essa proposta é profícua para criar uma ferramenta de diálogo intercultural e propiciar, em escala molecular, novas configurações narrativas e documentais, em novos regimes ou perspectivas críticas, desconstrutivas, ressignificantes, para as quais o "efeito" ou a "mediação" simbólica não deve ser desprezado.

Se essas coleções ficaram por décadas inacessíveis aos povos das quais as imagens foram tiradas, o uso da internet possibilitou um reencontro e, de forma virtual, uma repatriação imagética. O site permite acessar a fotografia, ter acessos às informações disponíveis sobre ela e fornecer novas informações que o usuário

10 Informações disponíveis em: 〈http://roots2share.nl> Acesso em: 29/07/2017.

11 Individuos que postam textos visando atrapalhar o objetivo do espaço disponibilizado para postagem. (descendente dos retratados) detenha. No entanto, por que não há histórias vinculadas a essas fotografias? Será que esse meio alcança todas as gerações? Os grupos interessados possuem acesso à internet? Essa plataforma deve ter continuidade a longo prazo? Por outro lado, a internet se representa pela fugacidade, talvez a potência desse uso esteja justamente em uma não pretensão de eternidade. A internet funciona como aquilo que Homi K. Bhabha (1998) denomina hibridismo ou terceiro espaço - ao menos potencialmente, e nesse plano ou nesse regime de documentação narrativa, nessas novas autorias e curadorias.

Bhabha voltou seu olhar para a cultura produzida na fronteira, entendendo-a como uma existência insurgente e intersticial (1998: 41). O interesse do autor pela fronteira está em analisar experiências transnacionais para pensar a realidade geopolítica produzida por essas conexões. O terceiro espaço se dá quando deixamos de lado os binarismos - ocidente versus oriente - e pensamos em termos de negociação, enquanto "articulação de elementos antagônicos ou contraditórios [...] que abrem lugares e objetivos híbridos de luta e destroem polaridades negativas entre o saber e seus objetos e entre a teoria e a razão prática-política." (Bhabha 1998: 52). A articulação ocorre entre elementos que se encontram em tensão, dando margem para o campo da diferença cultural. Desse modo, Bhabha nos diz que "o que se quer é demonstrar um outro território de tradução, um outro testemunho de argumentação analítica, um engajamento diferente na política de e em torno da dominação cultural." (1998: 60).

Produzir uma narrativa de/com indígenas dentro do museu, ou a partir dele, é ir além de um enfrentamento da colonialidade, é dar possibilidades para que a linguagem indígena adentre esses espaços de forma criativa. $\mathrm{O}$ uso da internet para repatriar fotografias dos groenlandeses sob a guarda de museus holandeses proporcionou, na perspectiva de nossa análise, a produção de um terceiro espaço. A interpretação dessas imagens poderá decorrer em ambiguidades e equívocos, o que não necessariamente será negativo. Antes de passar às considerações finais, vale talvez deixar indicado que o trajeto de observação 
nos traz então, no plano da internet, para uma espécie de sintoma epistemológico análogo àquele que se observou inicialmente no plano da escrita - considerada igualmente como um meio comunicacional, uma "coleção de habilidades socioambientais" diversa daquela que caracteriza o grafocentrismo moderno.

\section{Algumas considerações}

Em tom de conclusão, apontamos que apenas constatar a existência de uma construção da imagem do outro por parte da sociedade ocidental, e que tal imagem corroborou um discurso e uma ação de subjugação das linguagens e epistemologias desse outro, não se mostra suficiente. É preciso traçar formas de alargar o que é produzido nas fronteiras e disseminá-las: de modo mais claro, constatar que os museus ajudaram a construir a imagem do indígena como selvagem e para isso usaram seus objetos também não basta. Trazê-los para dentro da instituição só provocará efeitos interessantes quando tal inserção ocorrer no plano da horizontalidade, em que se considere, com a mesma intensidade, os argumentos, cosmologias, narrativas das sociedades indigenas, juntamente à lógica institucional.

Cabe ainda dizer que se trata de relações de poder e que mesmo quando a elaboração europeia prevaleceu (e ainda prevalece), houve agência indígena. De maneira alguma a violência colonial ocorreu sem resistência e sem insurgência: o uso da escrita por Poma de Ayala atuou como forma de mostrar o "bom governo" indígena. Martin Lienhardt, em seu livro La voz y la huella (1990), aponta no uso da escrita alfabética pelos indígenas uma submissão cultural. Entretanto, identificamos, como Rivera Cusicanqui (2010), uma crítica indígena no seio de uma ferramenta colonial, concluindo que enxergar a carta de Poma de Ayala apenas como submissão é um equívoco redutor. A própria incorporação da escrita pode ser vista como mais um símbolo da troca intercultural.

$\mathrm{Na}$ América Espanhola trouxemos brevemente o debate entre Sepúlveda e Las
Casas, a respeito dos direitos indígenas. Mesmo que atualmente a perspectiva de Las Casas tenha permanecido, algumas consequências problemáticas não devem ser anuladas. Immanuel Wallerstein (2007: 47) mostra os efeitos da ressonância do discurso de Las Casas nas discussões pós-coloniais: "a campanha pelos direitos humanos restaurou a ênfase de Sepúlveda no dever dos civilizados de suprimir a barbárie".

No que diz respeito às coleções, mostramos como sua coleta foi alvo de diversas narrativas ao serem incorporadas em museus. Por agora, gostaríamos de apontar que os movimentos museológico e antropológico que ocorreram no século XX não justificam por si só a inserção indígena nos museus, pois a demanda de desconstrução de narrativas impostas sobre os índios é proveniente das sociedades indígenas. Entendemos como "inserção indígena" aquela ação que acrescenta novos ares às instituições e horizontaliza o acesso e manejo dos acervos.

A curadoria compartilhada de coleções etnológicas não ocorre em um ambiente idílico em que todos os atores possuem a mesma voz, pois é confrontada por questões políticas e administrativas e pela disponibilidade física e de recursos da instituição e dos grupos a serem acionados. No entanto, esse aparece como o caminho mais profícuo como resposta às demandas pós-coloniais.

Embora nem todos os artefatos possam ser repatriados - por diversas razões nas quais não iremos adentrar - e nem sempre seja este o interesse dos indígenas, é necessário buscar caminhos para ampliar as possibilidades de acesso e curadoria das coleções. $\mathrm{O}$ site Roots2Share, como já mencionamos, é uma proposta gerada por duas instituições europeias (o Museon e o Museu Nacional de Etnologia) a partir de uma demanda dos gronelandeses em rever as fotografias tiradas por Gerti e Noortje Nooter, entre as décadas de 60 e 80 do século XX. A ferramenta propõe uma articulação possível de curadoria indígena e retorno de bens patrimonializados, mesmo quando o objeto em si encontra-se distante e salvaguardado em instituições ocidentais.

Visivelmente as ferramentas do site não são usadas na sua integralidade, o que traz 
questionamentos a respeito da efetividade da proposta. Todavia, mesmo que gere equívocos, propomos pensar a possibilidade de que o acesso às coleções etnográficas seja difundido por outros meios, sendo um deles a internet, para que, na ampliação das iniciativas, possamos analisar os desdobramentos a longo prazo da elaboração semelhante ao museu imaginário de Malraux (2011), mas indo além de uma nova percepção da obra de arte. Cada caso deve ser analisado segundo a demanda dos grupos implicados, pois há coleções que por diferentes motivos são problemáticas para serem divulgadas. De maneira semelhante, é necessário atentar para os riscos da apropriação indevida de símbolos culturais potencializada pela difusão das coleções por meios digitais (Brown 2003).

VIEIRA, M. Indigenous insertion integration in museums. R. Museu Arq. Etn., 30: 118-130, 2018.

\begin{abstract}
This work examines some shared curatorial actions within museums, examining the changes that former indigenous images have undergone, as represented through museological collections in a period of "national construction", until its reformulation in the post-modern and post-colonial debates, especially in the anthropological and museological fields. From 16th century on, such collections were built upon the key of the exotic, which in turn confirms the evolutionary and civilizing paradigm. In recent decades, the indigenous' performance in relation with, and sometimes within, old and new museums, institutions and projects, have been questioning in a creative manner Western appropriation of the image triggered by the artifacts, including those gathered by the indigenous to make the collection of their museums. In another complementary bias, internet comes up as a medium for image reclaiming, as shown by the Roots2Share website.
\end{abstract}

Keywords: Shared Curatory; Museums; Indigenous people; Image; Repatriation.

\title{
Referências bibliográficas
}

Bhabha, H.K.1998. O local da cultura. Editora UFMG, Belo Horizonte.

Boas, F. 1955. Primitive Art. Dover, New York.

Brown, M. F. 2003 Who owns native culture. Harvard University Press, Cambridge.

Bruno, M.C.O. 2008. Definição de Curadoria: os caminhos do enquadramento, tratamento e extroversão da herança patrimonial. In: Julião, L.; Bittencourt, J. (Orgs.). Cadernos de diretrizes museológicas 2: mediação em museus: curadorias, exposições, ação educativa. Secretaria de Estado de Cultura de Minas Gerais, Belo Horizonte, 14-23.

Buijs, C.; Van Broekhoven, L. 2010. Introduction. In: Van Broekthoven, L.; Bujs, C.; Hovens, P. Sharing knowledge \& cultural heritage: first nation of the Americas. Sidestone Press, Leiden, 7-16. Disponível em: <https://bit.ly/2SMNHbk>. Acesso em: 30/06/2017.

Cândido, M.M.D. 2003. Introdução. Cadernos de Sociomuseologia 20: 17-32. Disponível em: <https:// bit.ly/2YuBmO9>. Acesso em: 30/07/2017. 
Carelli, V. 2006. Iauaretê: Cachoeira das Onças. Olinda: Vídeo nas Aldeias. (Documentário em vídeo)

Clifford, J. 1998. A experiência etnográfica: antropologia e literatura no século XX. Editora UFRJ, Rio de Janeiro.

Clifford, J. 2009. Museologia e contra-história: viagens pela costa noroeste dos Estados Unidos. In: Abreu, R.; Chagas, M. (Orgs.). Memória e patrimônio: ensaios contemporâneos. Lamparina, Rio de Janeiro, 254-302.

Couto, I.H.P. 2012. A política institucional e o trabalho curatorial na montagem da exposição “Tempo e Espaço no Amazonas: os Wajãpi”. In: Cury, M.X.; Vasconcellos, C. de M; Ortiz, J.M. (Orgs.). Questões indígenas e museus: debates e possibilidades. Acam Portinari, Brodowski, 90-95.

Cunha, M.C. da. 1992. Introdução. In: Cunha, M.C. da (Org.). História dos índios do Brasil. Companhia das Letras, São Paulo, 9-24.

Cunha, M.C. da. 2009. Três peças de circunstância sobre direitos dos índios. In: Cunha, M.C. da. Cultura com aspas. Cosac Naify, São Paulo, 245-258.

Cury, M.X. 2009. Museologia, novas tendências. In: Granato, M.; Santos, C.P. dos; Loureiro, M.L. de N.M. Museu e museologia: interfaces e perspectivas. Mast, Rio de Janeiro, 8-42.

Fabian, J. 2004. On recognizing things: the "ethnic artefact" and the "ethnographic object". L'Homme 170: 47-60. Disponível em: <https://bit. ly/2OoKWyt>. Acesso em: 31/07/2017.

Fienup-Riordan, A. 2010. From consultation to collaboration. In: Van Broekthoven, L.; Bujs, C.; Hovens, P. Sharing knowledge \& cultural heritage: first nation of the Americas. Sidestone Press, Leiden: 1-6. Disponível em: <bit.ly/2SMNHbk>. Acesso em: 30/07/2017.

Françozo, M. de C. 2014. De Olinda a Holanda: o gabinete de curiosidades de Nassau. Editora Unicamp, Campinas.
Freire, J.R.B. 2009. A descoberta do museu pelos índios. In: Abreu, R.; Chagas, M. (Orgs.). Memória e patrimônio: ensaios contemporâneos. $2^{\text {a }}$ ed. Lamparina, Rio de Janeiro, 217-253.

Goody, J. 1996. Las consecuencias de la cultura escrita. In: Goody, J. (Org.). Cultura escrita en sociedades tradicionales. Gedisa, Barcelona, 11-38.

Goody, J. 2006. The theft of history. Cambridge University Press, Cambridge.

Gualtieri, R.C.E.; Dantes, M.A.M. 2001. Evolucionismo e ciência no brasil: museus, pesquisadores e publicações 1870-1915. 2001. Universidade de São Paulo, São Paulo.

Hall, S. 2013. Quando foi o pós-colonial? Pensando no limite". In: SOVIK, L. (Org.). Da diáspora: identidades e mediações culturais. Editora UFMG, Belo Horizonte, 110-140.

Hollanda, S.B. de. 2004. Visão do Paraíso: os motivos edênicos no descobrimento e colonização do Brasil. Brasiliense, São Paulo.

Las Casas, B. de. 2012. Treinta proposiciones muy jurídicas. In: Serna, M. (Ed.). La conquista del Nuevo Mundo: textos y documentos de la aventura americana. Castalia, Barcelona, 383-394.

Latour, B. 1994. Jamais fomos modernos: ensaio de antropologia simétrica. Editora 34, Rio de Janeiro.

Lestringant, F. 1997. O canibal: grandeza e decadência. Editora UnB, Brasília.

Lienhardt, L. 1990. La voz y su huella: escritura y conflicto étnico-social en América Latina (1492-1988). Casa de las Américas, La Havana.

Lyotard, J.-F. 2000. A condição pós-moderna. $6^{\mathrm{a}}$ ed. José Olympio, Rio de Janeiro.

Malraux, A. 2011. O Museu Imaginário. Edições 70, Coimbra. 
Meneses, U.T.B. de. 2005. A exposição museológica e o conhecimento histórico. In: Figueiredo, B.G.; VIDAL, D.G. (Orgs.). Museus: dos gabinetes de curiosidades à museologia moderna. Fino Traço, Belo Horizonte, 15-84.

Morel, M. 2000. Índios na vitrine: a "Exposição Anthropologica" de 1882 no Rio de Janeiro. Anais do 4 Ciclo de Conferências Brasil 500 Anos: Nação e Região, 2005, Rio de Janeiro.

Museu Índia Vanuíre. 2013. Índia Vanuíre. Disponível em: < https://bit.ly/2YszjGD>. Acesso em: 08/02/2017.

Nascimento, F.R. 2012. Curadoria: coleções etnográficas: os desafios de uma curadoria de etnologia atualizada. In: Cury, M.X., Vasconcellos, C. de M.; Ortiz, J.M. (Orgs.). Questões indígenas e museus: debates e possibilidades. Acam Portinari, Brodowski, 96-102.

Oliveira, J.P. de. 2012. A Refundação do Museu Maguta: Etnografia de um Protagonismo Indígena. In: Magalhães, A. M.; Bezerra, R.Z. (Org.). Coleções e colecionadores: a polissemia das práticas. Museu Histórico Nacional, Rio de Janeiro, 1, 201-218.

Poma de Ayala, F. 2005. Nueva Corónica y Buen Gobierno. Fondo de Cultura económica, Lima.

Possas, H.C.G. 2005. Classificar e ordenar: os gabinetes de curiosidades e história natural. In: Figueiredo, B.G.; Vidal, D.G. (Orgs.). Museus: dos gabinetes de curiosidades à museologia moderna. Fino Traço, Belo Horizonte, 151-162.

Poulot, D. 2013. Museu e museologia. Autêntica, Belo Horizonte.

Ribeiro, D. 19950 povo brasileiro: a formação e o sentido do Brasil. $2^{\mathrm{a}}$ ed. Companhia das Letras, São Paulo.
Rivera Cusicanqui, S. 2010. Ch'ixinakax utxiwa: una reflexión sobre prácticas y discursos descolonizadores. Tinta Limón, Buenos Aires.

Roca, A. 2015. Acerca dos processos de indigenização dos museus: uma análise comparativa. Mana, 21, 123-155.

Sahlins, M. 1997. O "pessimismo sentimental" e a experiência etnográfica: por que a cultura não é um “objeto" em via de extinção (parte I). Mana, 3, 41-73.

Sepúlveda, J.G. de. 2012. De las justas causas de la guerra contra los indios. In: Serna, M. (Ed.). La conquista del Nuevo Mundo: textos y documentos de la aventura americana. Castalia, Barcelona, 383-394.

Stengers, I. 2015. No tempo das catástrofes. Cosac Naify, São Paulo.

Stocking, G. 1985. Objects and others: essays on museums and material culture. The Wisconsin University Press, Madison.

Thomas, N. 2001. Introduction. In: PINNEY, C.; Thomas, N. (Ed.). Beyond aesthetics: art and the technologies of enchantment. Berg, Oxford, 1-12.

Trouillot, M.-R. 2003. Anthropology and the savage slot: the poetic and politics of otherness. In: Trouillot, M.-R. Global transformations: antropology and the modern world. Palgrave Macmillan, New York, 7-28.

Vieira, M. 2017. Narrativa dos ameríndios: disseminação de uma visão do contemporâneo. Dissertação de Mestrado. Universidade Federal do Estado do Rio de Janeiro, Rio de Janeiro.

Viveiros de Castro, E.B. 2002. A Inconstância da alma selvagem e outros ensaios de antropologia. Cosac \& Naify, São Paulo.

Wallerstein, I. 2007. O universalismo europeu: a retórica do poder. Boitempo, São Paulo. 